\title{
Erratum to: Beyond rational choice: How teacher engagement with technology is mediated by culture and emotions
}

\section{Carlo Perrotta ${ }^{1}$}

Published online: 22 January 2016

(C) Springer Science+Business Media New York 2016

\section{Erratum to: Educ Inf Technol \\ DOI 10.1007/s10639-015-9457-6}

In the original published version of this article two references were missing in Section Two: Empirical background and research questions. These references had been originally removed to anonymise the manuscript for peer review but were not added in the final, published article. The missing references are (Perrotta 2013) and (Perrotta and Evans 2013). The corresponding references in the reference list are reported below:

Perrotta, C. (2013). Do school-level factors influence the educational benefits of digital technology? A critical analysis of teachers' perceptions. British Journal of Educational Technology, 44(2), 314-327.

Perrotta, C., \& Evans, M. A. (2013). Instructional design or school politics? A discussion of 'orchestration' in TEL research. Journal of Computer Assisted Learning, 29(3), 260-269.

The online version of the original article can be found at http://dx.doi.org/10.1007/s10639-015-9457-6.

\section{Carlo Perrotta}

c.perrotta@leeds.ac.uk

1 School of Education, University of Leeds, Leeds LS2 9JT, UK 